\title{
Quality, phenolic compound and antioxidant activity of wines from Sangyod rice grain, paddy and husk during fermentation
}

\author{
Vilailak Klompong * \\ Department of Food Science and Technology, Thaksin University, Phatthalung, 93210, Thailand
}

*Corresponding author: vklompong@hotmail.com

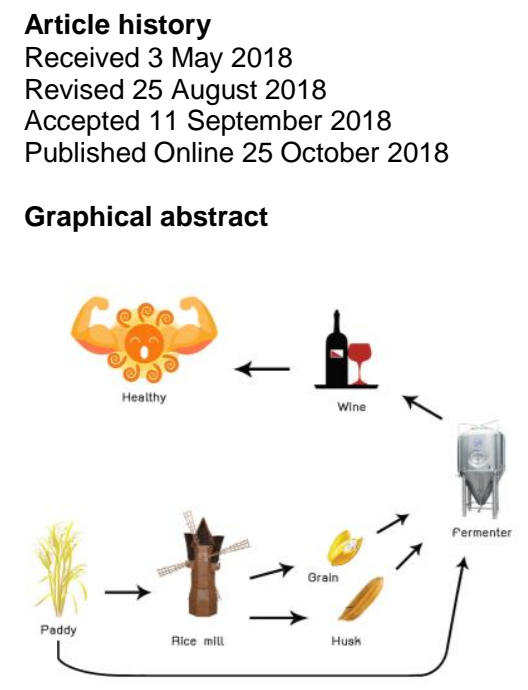

Published Online 25 October 2018

\section{Graphical abstract}

\begin{abstract}
The objective of this study was to utilize husk, byproduct from milling, and paddy of Sangyod rice that rich in bioactive compound to produce value added product as wine by reducing milling step of paddy. Quality changes, total phenolic content and antioxidant activity of wines from Sangyod rice grain, paddy and husk were monitored throughout the fermentation period. The acceptance of finished products from consumer drinking wine was also investigated. Alcohol content of three types of wine increased as the fermentation time increased. Paddy wine showed the fastest alcohol production following by rice grain and husk wine, respectively $(\mathrm{P}<0.05)$. Generally, total soluble solid and $\mathrm{pH}$ of wines decreases as the fermentation time increased. Yeast and mold increased throughout the fermentation time. As the fermentation time increased, total phenolic content and antioxidant activity including DPPH radical scavenging activity, ferric reducing antioxidant power (FRAP) and metal chelating activity increased throughout the fermentation period $(P<0.05)$ related to total phenolic content. Total phenolic content in three types of wines increased from 32-53 to $125-178$ (mg GAE/ml). Generally, paddy wine possessed the highest total phenolic content and antioxidant activities when compared with rice grain and husk wine $(\mathrm{P}<0.05)$. From the sensory evaluation including appearance, odor, taste and overall liking, the scores of rice grain and paddy wines were moderate, while the lowest scores in all attributes was observed in husk wine $(\mathrm{P}<0.05)$. Rice grain, paddy and husk wines obtained were amber in color $\left(L^{*}=10.11-16.27, a^{*}=8.07-14.91, b^{*}=10.8-12.18\right)$. Thus, the changes of quality, total phenolic contents and antioxidant activity of wine during fermentation were governed by raw material used and fermentation time. Additionally, Sangyod rice grain and paddy could be used as potential raw material for wine production and the wines obtained could be served as potential drinks for health, since containing bioactive compound as antioxidant.
\end{abstract}

Keywords: Wine, Sangyod rice, phenolic compound, antioxidant

\section{INTRODUCTION}

Rice (Oryza sativa L.) is consumed as a staple diet in many Asian countries (Xu et al., 2015). Sangyod rice is originated from Phatthalung province of Thailand and become geographical indicator (GI). After harvesting, paddy is milled to obtain rice grain, the waste or by-product from rice milling as husk is generated. Rice wine is an alcoholic drinks and widely consumed by people. Rice wine is produced from rice or glutinous rice by fermentation process using yeast and mold in a 2-step process involving saccharification (primary fermentation) and alcohol fermentation (secondary fermentation) (Jung et al., 2014; Yang et al., 2018)). Fermentation helps to preserve and enhance the nutritional value of foods and beverages (Lu et al., 2015). Rice wine is not only for drink but also for medical use in traditional medicine (Que et al., 2006) and has been associated with health-promoting effects for the abundant presence of phenolic compound in raw material, with respect to the antioxidant activity for the prevention of deleterious processes including cancer, diabetes, ageing, atherosclerosis, cardiovascular diseases and neurological disorders (Que et al., 2006; Wu et al., 2016; $\mathrm{Xu}$ et al., 2015). With the improvement of living condition, more and more people pay much attention to the health care function of food $(\mathrm{Wu}$ et al., 2016). Colored Sangyod rice contains high total phenolic content compared with white rice and could be used as raw material for rice wine fermentation. The objective of this study was to utilize husk, by product from milling, and paddy to reduce milling step of Sangyod rice that rich in bioactive compound to produce value added product as wine.

\section{EXPERIMENTAL}

\section{Materials}

2,2-Diphenyl-1-picryhydrazyl (DPPH) (PubChem CID: 2735032) and 2,4,6-tripyridyl-s-triazine (TPTZ) (PubChem CID: 77258) were purchased from Sigma-Aldrich, Inc. (St. Louis, MO, USA).

\section{Wine preparation}

Sangyod rice grain, paddy and husk were purchased from a supplier in Kohtoa village, Phatthalung province and transported to a laboratory, Thaksin University, Phatthalung. 200g of Sangyod rice grain, paddy and husk was added with $400 \mathrm{ml}$ of water, cooked and then cooled down to $35-40{ }^{\circ} \mathrm{C}$. To prepare koji, $4 \mathrm{ml}$ of spore suspension of Aspergillus oryzae $\left(2.7 \times 10^{7} \mathrm{cell} / \mathrm{ml}\right)$ and $4 \mathrm{ml}$ of suspension of Saccharomyces cerevisiae $\left(4.2 \times 10^{8} \mathrm{cell} / \mathrm{ml}\right)$ were added (Dung et al., 2005), mixed on tray, covered with sheet cloth and incubated at $30^{\circ} \mathrm{C}$ 
for 6 days. For preparing husk koji, rice flour was supplemented as carbon source ( 1 husk: 3 rice flour w/w). $20^{\circ}$ Brix of syrup was added in each bottle containing koji from Sangyod rice, paddy and husk to start fermentation. The fermentation continued at $25^{\circ} \mathrm{C}$ until alcohol content of each wine reached $12 \%$, approximately 12 days of fermentation. Alcohol content, total soluble solid, $\mathrm{pH}$, yeast and mold, total phenolic content and antioxidant activity were monitored throughout the fermentation period. Alcohol content, total soluble solid, $\mathrm{pH}$ and yeast and mold were measured using ebulliometer, refractometer, $\mathrm{pH}$ meter and hemocytometer, respectively. The rice wines obtained were also subjected to color measurment by colorimeter and the Hunter color values $\mathrm{L}^{*}$ (lightness), a* (redness), and $\mathrm{b}^{*}$ (yellowness) were reported.

\section{Determination of total phenolic content}

The total phenolic content of wines was investigated with a slight modification (Singleton and Rossi, 1965). One ml of wine was added with $9 \mathrm{ml}$ of deionized water. Thereafter, $1 \mathrm{ml}$ of Folin \& Ciocalteu's phenol reagent was added to the mixture and vortexed. After $5 \mathrm{~min}, 10$ $\mathrm{ml}$ of $7 \% \mathrm{Na}_{2} \mathrm{CO}_{3}$ solution was added and mixed well. Five $\mathrm{ml}$ of deionized water were added. After incubation for $90 \mathrm{~min}$ at $25^{\circ} \mathrm{C}$, the absorbance was read at $750 \mathrm{~nm}$. Gallic acid (20-100 mg/l) was used as standard. Total phenolic content was expressed as mg gallic acid equivalent (GAE) per ml.

\section{Determination of antioxidat activity}

\section{DPPH radical scavenging activity}

DPPH radical scavenging activity was measured with a slight modifcation (Yen and $\mathrm{Wu}, 1999$ ). To $2 \mathrm{ml}$ of wine samples, $0.5 \mathrm{ml}$ of 0.2 $\mathrm{mM}$ DPPH solution was added and mixed vigorously. Afer incubating for $30 \mathrm{~min}$, the absorbance of the resulting solutions was measured at $517 \mathrm{~nm}$ using a spectrophotometer (UV-1700 Pharma Spec, Shimadzu, Kyoto, Japan). DPPH radical scavenging activity was calculated as following:

\section{DPPH radical scavenging activity (\%)}

$$
=\left(1-\left(A_{517} \text { sample } / A_{517} \text { control }\right)\right) \times 100
$$

\section{Ferric reducing antioxidant power (FRAP)}

Acetate buffer $(0.3 \mathrm{M}, \mathrm{pH} 3.6)$ was prepared by dissolving $3.1 \mathrm{~g}$ $\mathrm{C}_{2} \mathrm{H}_{3} \mathrm{O}_{2} \mathrm{Na} \cdot 3 \mathrm{H}_{2} \mathrm{O}$ and $16 \mathrm{ml}$ of acetic acid in 11 of deionized water. TPTZ solution was prepared by dissolving $10 \mathrm{mmol}$ TPTZ in 11 of 40 $\mathrm{mM} \mathrm{HCl}$ solution. Ferric solution $(20 \mathrm{mM})$ was prepared using $\mathrm{FeCl}_{3} \cdot 6 \mathrm{H}_{2} \mathrm{O}$. The FRAP reagent was freshly prepared by mixing acetate buffer, TPTZ and ferric solutions at a ratio of 10:1:1. Five hundred $\mathrm{ml}$ FRAP reagent was mixed with $480 \mathrm{ml}$ of deionized water and was incubated at $37^{\circ} \mathrm{C}$ in a water bath for $10 \mathrm{~min}$, followed by adding $20 \mathrm{ml}$ of each wine sample. Afer $10 \mathrm{~min}$, the absorbance was read at $593 \mathrm{~nm}$. $\mu \mathrm{mol} / \mathrm{l}$ of ferric reduced to ferrous was reported (Benzie and Strain, 1996).

\section{Metal chelating activity}

The metal chelating activity on $\mathrm{Fe}^{2+}$ was investigated. One $\mathrm{ml}$ of wine was mixed with $3.7 \mathrm{ml}$ of deionized water. The mixture was then reacted with $0.1 \mathrm{ml}$ of $2 \mathrm{mM} \mathrm{FeCl}_{2}$ and $0.2 \mathrm{ml}$ of $5 \mathrm{mM} \mathrm{3-(2-pyridyl)-}$ 5,6-bis(4-phenyl-sulfonic acid)-1,2,4-triazine (ferrozine) for $20 \mathrm{~min}$ at room temperature. The absorbance was read at $562 \mathrm{~nm}$. Metal chelating activity was calculated as following (Decker and Welch, 1990).

Metal chelating activity $(\%)=\left(1-\left(A_{562}\right.\right.$ sample $/ A_{562}$ Control $\left.)\right) \times 100$

The control blank of each reaction was conducted in the same manner except that deionized water was used instead of sample. Sample blank was also prepared in the same manner of each reaction except that deionized water was used instead of working reagent.

\section{Sensory evaluation}

Three types of Sangyod rice wines were subjected to pasteurization before sensory evaluation. Sensory evaluation was conducted by 30 panel drinking wine in Thaksin University. Sensory attributes including appearance, odor, taste and overall linking were subjected to panelists for the 9-point hedonic scale (Meilgaard et al., 1990) including like extremely (9), like very much (8), like moderately (7), like slightly (6), neither like nor dislike (5), dislike slightly (4), dislike moderately (3), dislike very much (2) and dislike extremely (1). Sensory evaluation was conducted in a room with uniform source of light, absence of noise and disturbance at $20^{\circ} \mathrm{C} .15 \mathrm{ml}$ of wine samples were served using glass and drinking water was also provided for cleansing their palate between testing.

\section{Statistical analysis}

One-way ANOVA was used and mean comparison was performed by Duncan's multiple range test (Steel and Torrie, 1980). Statistical analysis was carried out using SPSS statistic program (Version 11.0) for Window (SPSS Inc. Chicago, IL).

\section{RESULTS AND DISCUSSION}

\section{Alcohol content, total soluble solid, $\mathrm{pH}$ and yeast and mold of Sangyod wines}

When wine fermentation started by adding syrup to koji, alcohol content of three types of wine increased as the fermentation time increased (Fig. 1a). Paddy wine showed the fastest alcohol production following by rice grain wine and husk wine, respectively $(\mathrm{P}<0.05)$. Husk wine showed the longest lag phase for alcohol production. That might be due to the nutrients composed in husk and rice flour not suitable for promoting alcohol production. Generally, total soluble solid (Fig. 1b) and pH (Fig. 1c) of wines decreased as the fermentation time increased $(\mathrm{P}<0.05)$. Total soluble solid of paddy wine showed the fastest decrease following by rice grain wine and husk wine, respectively, related to the increase of alcohol content. The $\mathrm{pH}$ of all Sangyod wines decreased from 7.1 to 3.9 at the end of fermentation. Yeast and mold increased throughout the fermentation time and started to decrease at the late phase of fermentation. Yeast and mold were in the range of 6.14 to $7.34 \mathrm{log} \mathrm{cfu} / \mathrm{ml}$ (Fig. 1d). Sangyod rice wines were brewed from rice grain, paddy, or husk with starter containing mold and yeast (Aspergillus oryzae and Saccharomyces cerevisiae) to produce amyloglucosidase, glucoamylase, $\alpha$-amylase, and $\beta$-glucuronidase to break down the starch into smaller carbohydrate polymers and sugar monomers, and also to liquefy the rice in primary fermentation (Que et al., 2006). During secondary fermentation, sugar from rice is converted into alcohol via fermentation by yeast (Lu et al., 2015). Alcohols are mainly generated by yeast metabolism (Yang et al., 2017) and lactic acid bacteria could produce lactic acid to decrease $\mathrm{pH}$. Yang et al. (2018) reported that $\mathrm{CO}_{2}$ production and reducing sugar decreased, while ethanol, total acidity and cell viability increased throughout the fermentation time. During fermentation, the relative contents of aldehydes, alcohols and esters increased rapidly because of the vigorous yeast growth. After that the relative content of alcohols and esters had increased slowly (Yang et al., 2018).

\section{Total phenolic content and antioxidant activity of Sangyod wines}

As the fermentation time increased, total phenolic content of Sangyod rice grain, paddy and husk wines increased (Fig. 2a) related to antioxidant activity including DPPH radical scavenging activity (Fig. 2b), FRAP (Fig. 2c) and metal chelating activity (Fig. 2d) $(\mathrm{P}<0.05)$. Paddy wine showed the highest total phenolic content at the beginning of fermentation throughtout the fermentation time, following by rice grain and husk wine. Generally, paddy wine possessed the strongest DPPH radical scavenging activity and metal chelating activity, following by husk and rice grain wines. However, husk wine exhibited the stronger FRAP than did paddy and rice grain wine. Various DPPH radical scavenging activity in different samples could be due to various phenolic compounds containing hydroxyl groups, which could donate $\mathrm{H}$-atom to DPPH radical to become stable molecule (Klompong and Benjakul, 2015). Chinese (Que et al., 2006; Wu et al., 2016; Xu et al., 2015) and Korean (Jung et al., 2014) rice wines were also reported to scavenge DPPH radical. 
a
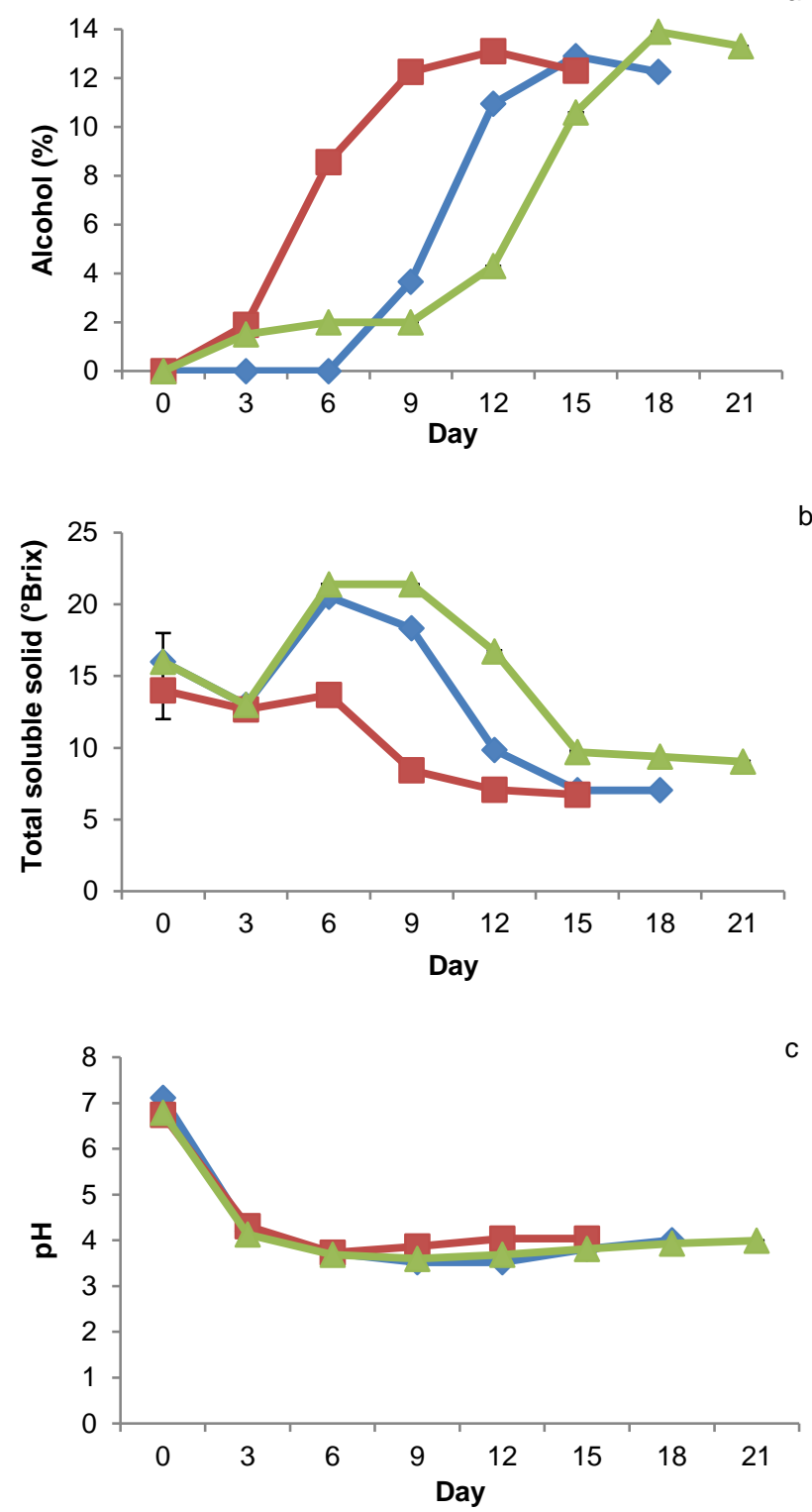

d



Fig. 1 Alcohol content (a), total soluble solid (b), pH (c) and yeast and mold (d) of wine from Sangyod rice grain ( - ), paddy ( - ) and husk (-) during fermentation.

For FRAP assay, it was conducted to estimate ability of reduce $\mathrm{Fe}^{3+}-\mathrm{TPTZ}$ complex to the ferrous form $\left(\mathrm{Fe}^{2+}\right)$ that reflect antioxidant power involving single electron transfer reaction (Klompong and Benjakul, 2015). Additionally, for metal chelating activity, phenolic compounds containing in wine might form complex with transition metal ions, therefore, those ions could not participate in metalcatalyzed initiation and hydroperoxide decomposition reactions
(Klompong and Benjakul, 2015). Lachman et al. (2007) and Xu et al. (2015) also reported that antioxidant activity increased during the winemaking process.
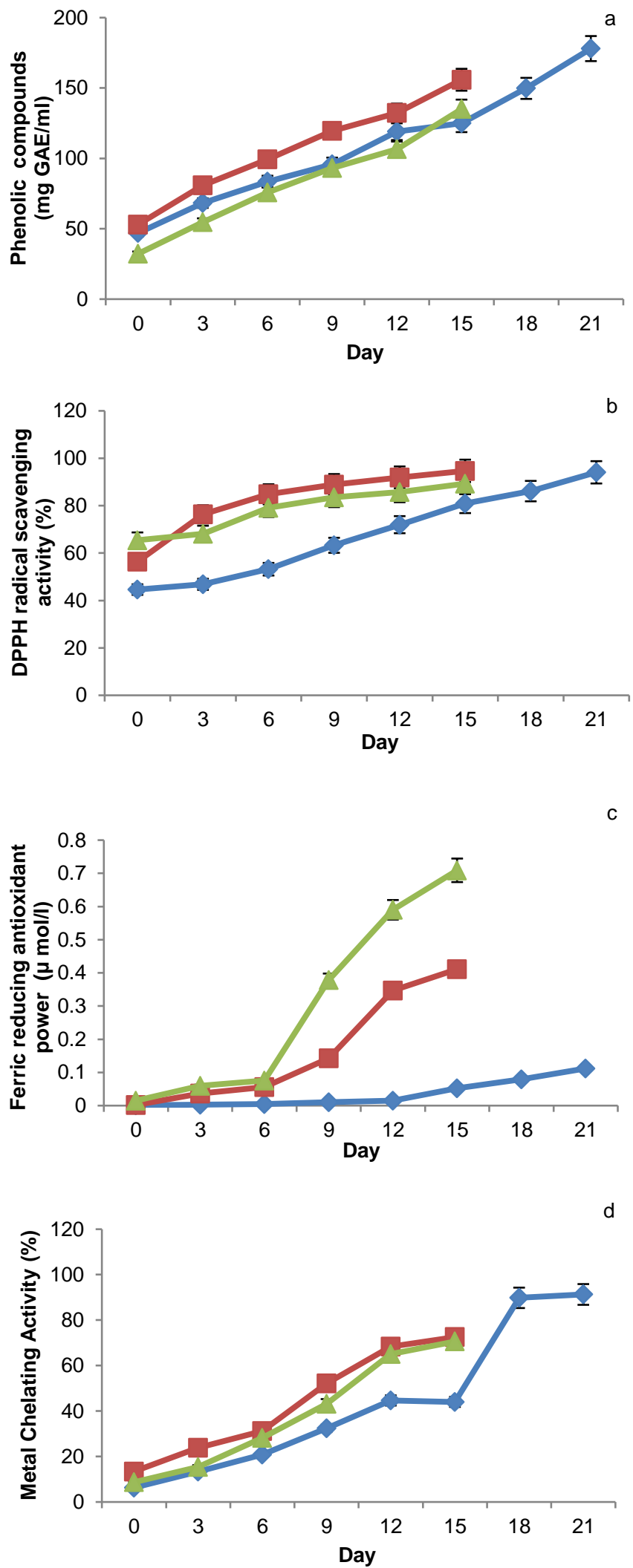

Fig. 2 Total phenolic content (a), DPPH radical scavenging activity (b), ferric reducing antioxidant power (c) and metal chelating activity (d) of wine from Sangyod rice grain ( -4 , paddy $(-)$ ) and husk $(-)$ during fermentation.

The polyphenolic substances, highly powerful antioxidant agents, in wine are given their capacity to scavenge free radicals (Lachman et 
al., 2007). Additionally, total phenolic contents strongly correlated with antioxidant activity (Chang et al., 2016; Que et al., 2006; Xu et al., 2015). By HPLC, phenolic compounds found in rice wines were caffeic acid, syringic acid, and rutin, epicatechin, catechin, gallic acid, vanillic acid, $p$-coumaric acid, $p$-hydroxybenzoic, ferulic acid and quercetin (Que et al., 2006; Xu et al., 2015). Catechin and syringic acid were the dominant phenolic compounds in rice wines, contributing about $60 \%$ to the total amount (Que et al., 2006; Xu et al., 2015). In some cases, chemical structure of phenolic compounds may be deterministic in exerting their antioxidant properties (Que et al., 2006). Rice wine also contains potentially bioactive components including amino acids, peptides, protein, oligo- and poly-saccharides, $\gamma$-Aminobutyric acid (GABA), phenolic compounds, Maillard reaction products, caminobutyric acid, vitamins, and mineral elements (Lu et al., 2015; Wu et al., 2016). The strong antioxidant activity can be attributed to various functional components contained in rice wine. A modified process to treat rice, extrusion and enzymatic hydrolysis, had been used to improve physicochemical properties, phenolic compound and antioxidant activities of wine and antioxidant activity contributed by soluble Maillard-derived reaction products generated during extrusion were closely related to phenolic compound (Xu et al., 2015). Ageing peroid also influenced antioxidant activity of wines (Oliveira et al., 2015).

\section{Color of Sangyod wines}

Rice grain, paddy and husk wines obtained were amber in color The lightness value $\left(\mathrm{L}^{*}\right)$ was in the range of 10.11-16.27 (Table 1). Wine from Sangyod rice grain show the highest lightness $\left(\mathrm{L}^{*}\right)$ following by paddy and husk, respectively $(\mathrm{P}<0.05)$. For the redness value ( $\left.\mathrm{a}^{*}\right)$, it was in the range of 8.07-15.61 and husk and paddy wines exhibited hihger $\mathrm{a}^{*}$ value than did rice grain wine $(\mathrm{P}<0.05)$. However, no significant difference was observed in yellowness $\left(b^{*}\right)$ among these wines. The difference in color of wine might be depended on raw material used in fermentation process. Rice grain, paddy and husk might contain different kinds and amonts of compounds including phenolic compound, pigment, amino acids, peptides, protein, oligo- and poly-saccharides, GABA, Maillard reaction products, c-aminobutyric acid, vitamins, and mineral elements. Different wine color also related to different antioxidant activity (Lachman et al., 2007).

Table 1 Color $\left(L^{*} a^{*} b^{*}\right)$ of wine from Sangyod rice grain, paddy and husk

\begin{tabular}{lccc}
\hline $\begin{array}{l}\text { Sangyod rice } \\
\text { wine }\end{array}$ & $\mathbf{L}^{*}$ & $\mathbf{a}^{\star}$ & $\mathbf{b}^{*}$ \\
\hline grain & $16.27 \pm 7.58^{\mathrm{c}}$ & $8.07 \pm 5.29^{\mathrm{a}}$ & $12.18 \pm 3.92^{\mathrm{ns}}$ \\
paddy & $12.90 \pm 4.30^{\mathrm{b}}$ & $14.02 \pm 5.21^{\mathrm{b}}$ & $13.12 \pm 4.51$ \\
husk & $10.11 \pm 4.72^{\mathrm{a}}$ & $15.61 \pm 4.34^{\mathrm{b}}$ & $11.74 \pm 7.27$
\end{tabular}

Mean \pm SD from triplicate determinations.

${ }^{a-c}$ Different lowercase superscripts in thesame column indicate significant difference $(\mathrm{P}<0.05)$

ns No significant difference

\section{Sensory evaluation of Sangyod wines}

During this fermentation process, the sensory attributes of Sangyod wine were developed. Sangyod rice grain and paddy wines showed high score when compared with husk wine (Fig. 3). Some substances developed during fermentation might affect sensory attributes of husk wine and also affect FRAP of husk wine (Fig 2c). No difference was observed in appearance, odor, taste and overall liking between wines from Sangyod rice grain and paddy. Since rice wine is produced from rice by saccharification with mold and fermentation with yeast (Saccharomyces cerevisiae), the enological characteristics of different yeast strains have greatly impact on the quality of the resulting wines. Yeast fermentation not only produce ethanol, but also generate volatile flavor metabolites, which were resulted in the specific character and style of rice wine. Yeast starters have been proven that could improve the flavor of rice wine (Yang et al., 2018). The quality of the resulting wines including yellowness, turbidity, alcohol aroma, fruit aroma, cereal aroma, sweet, sour, bitter, astringency, continuation and full body also depended on the enological characteristics of different yeast strains. Yang et al. (2017) found that wines fermented with different starters exhibited different kind and amount alcohols, esters and volatile compounds. Short-chain fatty acid ethyl esters were main flavor substances during fermentation, whereas long-chain fatty acid ethyl esters were typical compounds after clarification and sterilization. Appearance (color and turbidity), aroma (alcohol and cereal), taste (sweet, sour and bitter) and overall linking might include mouthfeel (astringency, continuation and full body) were chosen to characterize the sensory properties of rice wine samples (Yang et al., 2018).

Rice wine is a complex mixture of hundreds of flavor compounds including volatile aromas that arise from its raw materials and the products of microbial metabolism present within the different brewing processes (Yang et al., 2017). In addition, phenolic compounds are also responsible for the characteristic taste, flavor and astringency of wine (Wu et al., 2016). Wine aroma, a number of volatile compounds produced during fermentation, is one of the most important factors governing the hedonic quality and consumer preference ( $\mathrm{Lu}$ et al., 2015; Yang et al., 2018). The sensory quality plays a major role in product acceptability by directly influencing the success of a product in the marketplace (Ouyang et al., 2018).

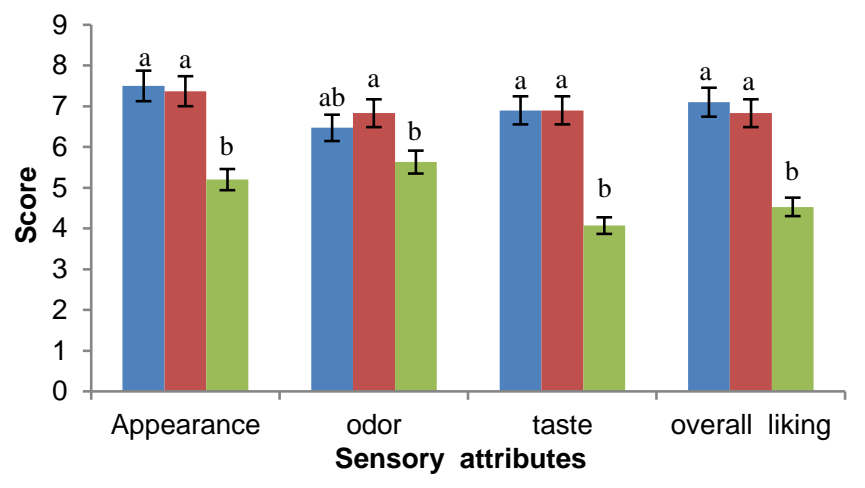

Fig. 3 Sensory evaluation of wines from Sangyod rice grain ( $\square$ ), paddy ( ) and husk ( ).

Yang et al. (2018) reported that flavor compounds mainly found in Chinese rice wine were 13 alcohols, 28 esters, 8 aldehydes, 2 phenols, 2 ketones and 4 acids. This showed that starters used in wine fermentation played an important role on the numbers of alcohols and esters. The taste of Chinese rice wine is derived from the mutual coordination of the alcohols, esters and aldehydes that make up the structural components of rice wine aroma. The relative content of aldehydes increased slightly faster than that of alcohols and esters during secondary fermentation. Key substances identified among the alcohols included 3-methyl-1-butanol, 2-phenyethanol and 2-methyl-1propanol. Their amounts accounted for above $95 \%$ of the total content of alcohols. The different fermentation stages of winemaking produce their own unique combinations of volatile flavor compounds. Jung et al. (2014) also reported that Korean rice wine considered to have health benefits, because it contains various ingredients such as proteins, sugars, vitamins, bioactive compounds and organic acids. Wine is characterised by flavors of bitterness, sourness, sweetness, saltiness and umami and the addition of various wild-type yeasts and raw materials during fermentation was found to affect the chemical characteristics and volatile compound profiles in the Korean traditional rice wine. Among the volatile compounds produced, short- and long-chain esters were affected, depending on the yeast strains. The types of yeast strains and the degrees of milling of the rice greatly affected the chemical and volatile compounds of the glutinous rice wines. An increase in the degree of milling decreases the alcohol, amino acid and organic acid contents, but increases the soluble solids, degree of color, ultraviolet absorbance and reducing sugar and free sugar contents (Jung et al., 2014).

The quality and distinct polyphenol composition of rice wines related with the rice variety, raw material (Xu et al., 2015), type of koji used in the fermentation process and storage time (Que et al., 2006). 


\section{CONCLUSION}

Sangyod rice grain, paddy and husk wines contained bioactive compound and possessed antioxidant activity including DPPH radical scavenging activity, ferric reducing antioxidant power and metal chelating activity. The changes of quality including alcohol content, total soluble solid, $\mathrm{pH}$, yeast and mold, total phenolic contents and antioxidant activities of Sangyod wines were designated by raw material used and duration of fermentation. Color and sensory quality of Sangyod rice wines were also determined by raw material used. Sangyod rice grain and paddy could be used as potential raw material for wine production and the wines obtained could be served as potential drinks for health.

\section{ACKNOWLEDGEMENT}

This work was financially supported by faculty of technology and community development, Thaksin university, Thailand.

\section{REFERENCES}

Benzie, I.F., Strain, J.J. 1996. The ferric reducing ability of plasma (FRAP) as a measure of "antioxidant power": The FRAP assay, Anal. Biochem. 239, 7076.

Chang, T.C., Jang, H.D., Lin, W.D., Duan, P.F. 2016. Antioxidant and antimicrobial activities of commercial rice wine extracts of Taiwanese Allium fistulosum. Food Chem. 190, 724-729.

Decker, E.A., Welch, B. 1990. Role of ferritin as a lipid oxidation catalyst in muscle food. J. Agric. Food Chem. 38, 674-677.

Dung, N.T.P., Rombouts, F.M., Nout, M.J.R. 2005. Development of defined mixed-culture fungal fermentation starter granulate for controlled production of rice wine. J. Food Sci. Emerg. Technol. 6, 429-441.

Jung, H., Lee, S.J., Lim, J.H., Kim, B.K., Park, K.J. 2014. Chemical and sensory profiles of makgeolli, Korean commercial rice wine, from descriptive, chemical, and volatile compound analyses. Food Chem 152, 624-632.
Klompong, V., Benjakul, S. 2015. Antioxidative and antimicrobial activities of the extracts from the seed coat of Bambara groundnut (Voandzeia subterranea). RSC Adv. 5, 9973-9985.

Lachman, J., Sulc, M., Schilla, M. 2007. Comparison of the total antioxidant status of Bohemian wines during the wine-making process. Food Chem. 103, 802-807.

Lu, Q.Y., Lee, R.P., Huang, J., Yang, J., Henning, S.M., Hong, X., Heber, D., Li, Z. 2015. Quantification of bioactive constituents and antioxidant activity of Chinese yellow wine. J. Food Comp. Anal. 44, 86-92.

Meilgaard, M., Civille, G.V., Carr, B.T. 1990. Sensory Evaluation Techniques. Florida, USA: CRC Press, Inc.

Oliveira, H., Fernandes, I., de Freitas, V., Mateus, N. 2015. Ageing impact on the antioxidant and antiproliferative properties of Port wines. Food Res. Inter. 67, 199-205.

Ouyang, Q., Chen, Q., Zhao, J. 2016. Intelligent sensing sensory quality of Chinese rice wine using near infrared spectroscopy and nonlinear tools. Spectrochim. Acta. 154, 42-46.

Que, F., Mao, L., Pan, X. 2006. Antioxidant activities of five Chinese rice wines and the involvement of phenolic compounds. Food Res. Inter. 39, 581-587.

Singleton, V.L., Rossi, J.A. 1965. Colorimetry of total phenolics with phosphomolybdic-phosphotungstic acid reagents. Am. J. Enol. Vitic. 16, 144-158.

Steel, R.G.D., Torrie, J.H. 1980. Principles and procedures of statistics: A biometrical approach. McGraw-Hill, New York,

Wu, Z., Xu, E., Long, J., Pan, X., Xu, X., Jin, Z., Jiao, A. 2016. Comparison between ATR-IR, Raman, concatenated ATR-IR and Raman spectroscopy for the determination of total antioxidant capacity and total phenolic content of Chinese rice wine. Food Chem. 194, 671-679.

Xu, E., Wu, Z., Long, J., Wang, F., Xu, X., Jin,Z., Jiao, A. 2015. Improved bioaccessibility of phenolics and antioxidant activity of glutinous rice and its fermented Chinese rice wine by simultaneous extrusion and enzymatic hydrolysis. J. Funct. Foods. 17, 214-226.

Yang, Y., Xia, Y., Lin, X., Wang, G., Zhang, H., Xiong, Z., Yu, H., Yu, J., Ai, L. 2018. Improvement of flavor profiles in Chinese rice wine by creating fermenting yeast with superior ethanol tolerance and fermentation activity. Food Res. Inter. 108, 83-92.

Yang, Y., Xia, Y., Wang, G., Yu, J., Ai, L. 2017. Effect of mixed yeast starter on volatile flavor compounds in Chinese rice wine during different brewing stages. LWT - Food Sci. Technol. 78, 373-381.

Yen, G., Wu, J. 1999. Antioxidant and radical scavenging properties of extract from Ganoderma tsugae. Food Chem. 65, 375-379. 